\title{
Meta-Gig: Empowering anyone to create crowd marketplaces
}

\author{
Carlos Toxtli, Saiph Savage
}

Published: 30 November 2020

\begin{abstract}
Few have the power to create crowd markets. Existing marketplaces may thus not embody workers' or requesters' needs. In this paper, we imagine a future where anyone could create the crowd markets they desire. We study the characteristics of the markets that 40 workers and 40 requesters from Amazon Mechanical Turk propose. We uncover that workers pushed for marketplaces that either empowered workers to set their own salaries without requiring a minimum wage or had intelligent algorithms that could automatically decide the salaries while also ensuring everyone received a minimum wage. Requesters were consistent in their preference of paying by commission and preferred markets that automatically set the salary. Both workers and requesters advocated for mechanisms to ensure quality and flexible time schedules in the market. We conclude by discussing design implications from our findings.
\end{abstract}

\section{Keywords:}

Crowdsourcing; Gig Markets; System; Iterative Design Co-Design; User Involvement; Implications for Design.

\section{Introduction}

Most crowd markets, such as Amazon Mechanical Turk, Task Rabbit, or Upwork, are owned and defined by a small group of individuals [2]. Workers and requesters typically have little agency in deciding or changing the characteristics of the marketplaces where they work, let alone working to define what types of crowd markets exist - in terms of the markets' functionality or the type of work and professions supported or facilitated on these platforms [21]. This generates asymmetrical labor relationships, as those with the power to design the market might not have the workers' best interest in mind or even understand them [15][32][41]. Therefore, even if current crowd markets might have demonstrated strong

\footnotetext{
Toxtli, C

West Virginia University

Morgantown, West Virginia

carlos.toxtli@mail.wvu.edu

Savage, S

Universidad Nacional Autónoma de México

Mexico City, Mexico

saiph.savage@mail.wvu.edu
}

potential to bring new work opportunities [30], they might not address the needs of all involved actors.

Additionally, it is unclear what types of marketplaces workers or requesters would define for themselves if given the opportunity. Would their visions be constrained to modifying the marketplaces they already know? What would the core differences be between the markets that workers and requesters want to construct? Understanding this can help design the next generation of crowd markets, as we will be able to better identify what matters to the different stakeholders, better consider their stakes in the design, and better support all stakeholders of the system.

In this paper we imagine a future where anyone can have the tools to create any market with the characteristics that they desire, e.g., we envision platforms that allow anyone to simply manipulate a set of parameters and create a marketplace that adheres to the characteristics and aspects that they define. This would be similar to the set of WordPress tools that allow anyone to set up and create their desired online stores [5] which lowered the bar of entry to selling wares online, we imagine a future where any worker or requester is empowered to define their own marketplace and lower the bar to selling labor online. In this paper, we present our investigation of the types of markets that workers and requesters propose given these capabilities. We work specifically with workers and requesters recruited from one of the most popular crowd markets, Amazon Mechanical Turk [3]. We focus on the following research question:

- What type of crowd markets do workers and requesters propose, and how are they similar/different?

To address this question, we built META-GIG, a crowd marketplace definition tool we implemented as a web platform. We use META-GIG as a design probe to indirectly question workers and requesters about what they currently lack in crowd markets. META-GIG uncovers the type of marketplace that workers and requesters envision by let them configure settings related to hireability, wage, reputation, and work schedule. Previous work [31][34][46] has identified these features as key variables to define different types of online markets and their work dynamics. We recruited 40 workers and 40 requesters to define their own crowd markets in META-GIG.

In this paper we make two contributions, we outline: (1) the type of crowd markets that workers and requesters envision and the specific needs they uncover; (2) implications for the design of future crowd marketplaces. 


\section{Related Work}

Crowdsourcing marketplaces such as Mechanical Turk and Upwork have created opportunities for workers and requesters to generate income and get work done. However, there are multiple areas where challenges still exist and have not been addressed properly. Previous research has found challenges in areas such as wages and quality of work. Requesters are often surprised by lowquality results [33], and workers often receive negative feedback or no pay for their time spent searching for tasks [28]. This produces a downward spiral whereby workers feel justified in producing lower quality work and requesters drive down wages [31]. Previous work has demonstrated that by providing immediate feedback to workers, they produced better overall work and revised their work more carefully [20].

Another challenge area is reputation. Even though crowdsourcing platforms suffer from low-quality work and unfair rejections, paradoxically, most workers and requesters have high reputation scores [33]. This is partly due to misaligned incentives between requesters and workers [26]. Reputation is important as it can have serious financial consequences, motivating people to manipulate systems for their own benefit, such as monetary rewards [34]. Past research has tried to improve trust in crowdsourcing through upstream fixes, such as proposing that crowd workers who collectively certify each other's quality through double-blind peer assessment [51].

Location and privacy is another issue, as it has been proposed that platforms should disclose enough information to be trusted as a source of worker quality while also maintaining his privacy [10]. Previous work has documented that greater transparency may be helpful in markets such as eBay and Amazon, but such mechanisms must be carefully managed to avoid abuse [17], but little we know about the privacy concerns of workers and requesters.

Work schedule and Hireability, especially related to synchronous or asynchronous collaboration is a major issue for online marketplaces [34]. The challenge relates to the availability of workers and the possibility of orchestrating on-demand crowds [46]. Retelny et al. developed a crowdsourcing platform to handle complex tasks which opened the door to a range of higher-level workflows that can assume expert knowledge; However, it was tested with self-managing teams and not with teams led by project managers.

Previous research has highlighted the necessity of conceptualizing and prototyping new forms of crowd work that are common today and propose future directions [34]. With this research, we aim to lead the path to the design principles that will form the foundation of future crowd work marketplaces. By using the feedback obtained from market participants, we shed a light into the motivations and aims of both parts to design more equitable marketplaces that can tackle the needs of workers and requesters.

\section{Meta-Gig}

META-GIG is a platform that allows anyone to define their own crowd market. To establish the rules of how their marketplace will function, META-GIG guides people to configure the different features of their crowd market (e.g., the wages).

To elicit information on how the user imagines her marketplace, i.e., how she wants to configure the different features, META-GIG uses a series of questions, including both open-ended and multiple-choice questions. Figure 1 presents META-GIG's interface for elicitating information from users. The interface consists of two main areas:

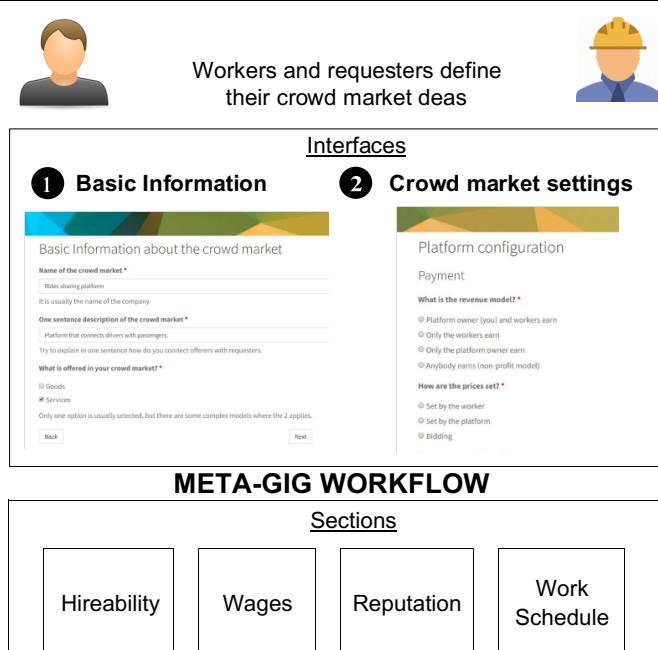

Figure 1. The META-GIG workflow includes specifying information about hireability, waged, reputation, and work schedule. market participants, we shed a light into the motivations and aims of both parts to design more equitable marketplaces.

1) Basic information. In this step, people establish the basic information about their crowd market, such as its name and a textual description specifying the type of work that will get done on the platform, type of workers and requesters who will participate (e.g., "Its a crowd market for providing real time psychological support to US Veterans. Workers are psychologists trained in PTSD, who can provide psychological support. Requesters are US veterans").

2) Crowd market settings. Here, people configure different features of their crowd market to establish its rules. In specific, people focused on configuring how the following four features would look like in their marketplace, which prior research identified as key to establish the crowd market's rules [24]. Notice that users configured the four different features following standards from prior work [38]. Details on the specific features and how users could configure them is presented in Table 1 and in the following: (1) Hireability: Who works on the market? Are they specialists? are they local or remote workers? People configure here the occupations (profile) of the type of workers they looked to hire. Users provide this information via an open-ended question where they provide a textual description of their desired workers. Users also specified whether they expected the workers to work remotely, locally, or both. Users configured this latter parameter via a multiple-choice question.

(2) Wages: Who establishes the wages and what type of wages exist? Here, users first configure who sets the wages on their crowd marketplace by completing a multiple-choice question where they select either: "workers,"

"requesters," or "the platform (i.e., an algorithm)," as the entity that will establish the salaries on their market. Next, users select the type of earnings that would exist on their platform. People again complete a multiple-choice question where they select whether they want to have "a minimum wage", "minimum wage plus the earning obtained in the platform", or "only the earnings obtained on the platform".

(3) Reputation: How is the reputation of workers and requesters established? What mechanisms to set a person's reputation exist? Can everyone view others' reputation? Users first configure via a binary question whether the reputation of a particular actor 
(workers or requesters) is "visible" or "not visible" to others on the market. Next, users establish also via a binary question whether background checks (screenings) exist for workers or requesters who want to join the market. Finally, users also set via a binary question whether people's reputation is affected by the interactions or work they produce on the market.

(4) Work Schedule: Who establishes the work schedule on the crowd market? Users select here via a multiple-choice question whether "workers," "requesters," or "the platform (i.e., an algorithm)" set the work schedule on the marketplace.

Table 1. Overview of the crowd market features that users could configure. Parameter denotes the different aspects of the feature that users could set. Type corresponds to how users were asked to configure each specific parameter of a feature. Description provides an overview of each feature and the parameters people could configure.

\begin{tabular}{|c|c|c|c|}
\hline Feature & Parameter & Type & Description \\
\hline \multirow[t]{2}{*}{ Hireability } & $\begin{array}{l}\text { Worker } \\
\text { occupation }\end{array}$ & $\begin{array}{l}\text { Open- } \\
\text { ended }\end{array}$ & $\begin{array}{l}\text { Coded as } \\
\text { "Specialized" or } \\
\text { "Not Specialized" } \\
\text { (ISCO08 catalog) }\end{array}$ \\
\hline & $\begin{array}{l}\text { Worker } \\
\text { presence }\end{array}$ & $\begin{array}{l}\text { Multiple } \\
\text { choice }\end{array}$ & Remote or Local \\
\hline \multirow[t]{2}{*}{ Wage } & $\begin{array}{l}\text { Type of } \\
\text { Earnings }\end{array}$ & $\begin{array}{l}\text { Multiple } \\
\text { choice }\end{array}$ & $\begin{array}{l}\text { "Include minimum } \\
\text { wage" or "Not } \\
\text { include minimum } \\
\text { wage" }\end{array}$ \\
\hline & $\begin{array}{l}\text { Salary set } \\
\text { by }\end{array}$ & $\begin{array}{l}\text { Multiple } \\
\text { choice }\end{array}$ & $\begin{array}{l}\text { "Workers" or } \\
\text { "Requesters" or } \\
\text { "by the Platform" }\end{array}$ \\
\hline \multirow[t]{3}{*}{ Reputation } & Visibility & Binary & $\begin{array}{l}\text { Visible for } \\
\text { Workers and/or } \\
\text { Requesters }\end{array}$ \\
\hline & Screening & Binary & $\begin{array}{l}\text { Background checks } \\
\text { for Workers and/or } \\
\text { Requesters }\end{array}$ \\
\hline & $\begin{array}{l}\text { Work } \\
\text { affects } \\
\text { Reputation }\end{array}$ & Binary & $\begin{array}{l}\text { Work or } \\
\text { interactions on } \\
\text { crowd market } \\
\text { affects reputation }\end{array}$ \\
\hline $\begin{array}{l}\text { Work } \\
\text { Schedule }\end{array}$ & Schedule & $\begin{array}{l}\text { Multiple } \\
\text { choice }\end{array}$ & $\begin{array}{l}\text { Set by Requester, } \\
\text { or Worker, or } \\
\text { Platform }\end{array}$ \\
\hline
\end{tabular}

\section{Meta-Gig Field Deployment}

We conducted a field deployment where 40 workers and 40 requesters used META-GIG to configure the rules of their desired crowd market. Specifically, we asked workers and requesters to configure four main features of their marketplace, which previous work identified as key [48]. We investigate how workers and requesters configured these features to indirectly start to study: (1) the needs of workers and requesters in current markets; (2) the advantages, limitations, and future of crowd market creation tools.

\subsection{Method}

We recruited 40 workers ( 19 women and 21 men) and 40 requesters (22 women and 18 men) with varying experience on Amazon Mechanical Turk, one of the most popular and largest crowd markets [44]. The ages of the participants ranged from 18 to 58 years old. The population of 40 requesters included professionals and academic requesters, with a skew toward academics. The 40 workers meet the requirements of having completed more than 500 Human Intelligence Tasks (HIT) and an acceptance rate higher than $95 \%$. The study lasted roughly an hour, so we paid workers \$9 USD in line with current ethical standards on Mechanical Turk [10].

Table 2. Overview of the percentage of workers and requesters who configured the four features of their crowd markets in a particular way ( $W=$ Workers $R=$ Requesters).

\begin{tabular}{|l|l|l|l|}
\hline Category & Feature & $\mathrm{W}$ & $\mathrm{R}$ \\
\hline Hireability & Specialized Occupation & $55 \%$ & $57 \%$ \\
\hline & Work Locally & $55 \%$ & $53 \%$ \\
\hline Wage & No Minimum wage & $55 \%$ & $65 \%$ \\
\hline Reputation & Platform sets salary & $53 \%$ & $55 \%$ \\
\hline & Screen workers & $82 \%$ & $75 \%$ \\
\hline & Screen requesters & $55 \%$ & $45 \%$ \\
\hline & Show worker reputation & $85 \%$ & $85 \%$ \\
\hline & $\begin{array}{l}\text { Show requester } \\
\text { reputation }\end{array}$ & $75 \%$ & $75 \%$ \\
\hline Work schedule & $\begin{array}{l}\text { Work affects } \\
\text { Reputation }\end{array}$ & $71 \%$ & $90 \%$ \\
\hline & Set by worker & $40 \%$ & $35 \%$ \\
\hline & Set by requester & $40 \%$ & $48 \%$ \\
\hline
\end{tabular}

Participants were told to use META-GIG to create a crowd market defined in their own terms. We had participants first provide a short description of the crowd market they envisioned, specifying the type of labor workers would do, and how requesters and workers would operate on their platform. Next, participants configured via META-GIG's interface how hireability, wages, reputation, and work schedule would function on their markets.

We used Upwork to hire 3 English-speaking college-educated individuals to categorize all proposed occupations in the crowd markets ideas according to the International Standard Classification of Occupations (ISCO08) [43]. First, we asked two coders to categorize each of the 80 proposed crowd market ideas into one of the occupations (the "most relevant" one). For each crowd market they categorized, coders read the description of the crowd market and saw an overview of the configured parameters. We had a Cohen's kappa of .82. We then asked the third coder to label the crowd market ideas upon which the first two coders had disagreed. We used a "majority rule" approach to determine the theme for these crowd market ideas.

For each of these four features, we measured how much workers and requesters configured each feature in a particular way. We grouped crowd markets with similar feature configurations. For each feature and for each of its groups, we read through the textual 
descriptions of the markets in the group. This helped us to further understand why people might have configured a feature in a specific form. Table 2 presents the most common ways workers and requesters configured each of the four features. Next, we present details of how workers and requesters set each of these four features for their crowd markets.

\subsection{Results}

Hireability. From Table 2 we note that both workers and requesters envisioned in their marketplaces to primarily hire specialized professions (specialized according to ISCO08 standards), and also mainly hire locals. We defined as "Not specialized" occupations the ideas based on goods where the workers basically offer their belongings, or the worker role fit into the "Elementary occupations" category. The rest of the occupations were defined as "Specialized".

Figure 2. Overview of how workers and requesters configured the Hireability feature in their crowd markets.

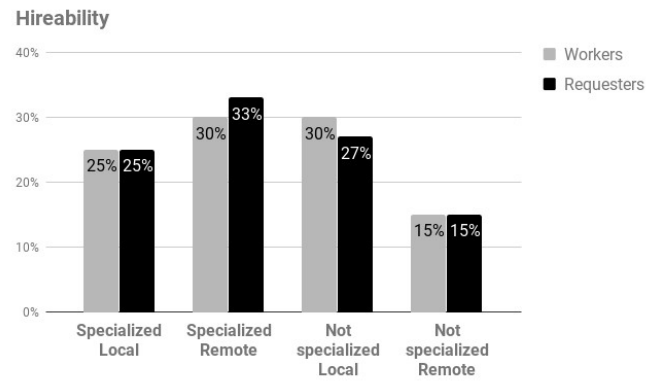

However, when we dig deeper and study exactly how these two parameters were jointly configured (see Fig. 2), we note that both workers and requesters tended to establish markets where specialists would be hired to work remotely, and non-specialists were hired for local jobs.

Additionally, while from Fig. 2 it might appear that workers and requesters envisioned hiring specialists and non-specialists for similar purposes, we identified differences in the professions they established they would hire. Requesters tended to imagine scenarios where they hired a larger variety of occupations. Collectively, requesters imagined crowd markets that incorporated 8 of the 10 professions listed in the International Standard Classification of Occupations (ISCO08), whereas workers only considered 6 .

Workers tended to propose hiring professionals who operated within offices, such as lawyers or managers.

"...I would like to create a service that will pair people who need financial assistance with finance experts ..." (Participant \#23, female, 38 years old)

Requesters, in contrast, imagined their crowd markets would hire individuals who operated from a variety of spaces. Some requesters, e.g., proposed markets that would hire workers specializing in agricultural and who operated within ranches.

"...The platform connects local farmers with people who want to buy locally and sustainable ..." (Participant \#17, male, 26 years old)

Another requester imagined hiring workers who operated from hospitals:

"...The platform connects people who need the service (patients) with people who can offer it (nurse) ...” (Participant \#2, female, 45 years old)
Wages. From Table 2 we observe that both workers (55\%) and requesters $(65 \%)$ primarily envisioned crowd markets where a minimum wage did not exist and pushed for marketplaces where wages were set by the platform (i.e., by an algorithm).

However, when we dig deeper (see Fig.3), we note that in settings where a minimum wage was nonexistent, workers and requesters actually differed in "who" should determine workers' salary. In this setting, workers $(33 \%)$ primarily proposed crowd markets where the workers themselves had the agency to set their own wages. While a large number of requesters $(25 \%)$ did also push for this setting, an equal number also envisioned the wages would be algorithmically set by the platform. Here, requesters appeared to believe algorithms were the best way to ensure fairness:

“...[I envision my crowd market will] employ artisans or people who make handicrafts in our country [...] We need algorithms to control the prices of their labor, if not their crafts are often sold on public roads too cheaply or subject to haggling..." (Participant \#22, female, 40 years old)

Figure 3. Overview of how workers and requesters configured the Salary (Wages) feature in their crowd markets.

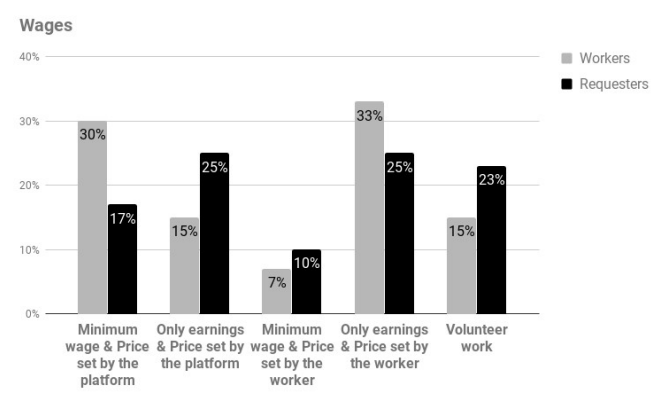

From Fig. 3 we also realize that when workers and requesters set a minimum wage, they primarily envisioned an algorithm to define the wages and not a human.

Interestingly, both workers $(5.9 \%)$ and requesters $(6.5 \%)$ rarely proposed crowd markets where requesters had to set the salary (i.e. bidding). What they did envision were crowd markets where salaries simply did not need to be established because the markets only had volunteer work. However, there was a tendency where requesters and workers would exchange goods between each other (even if a formal salary did not exist). An example of such type of marketplace:

"...I would like to create a service that pairs people who need financial aid with those who are financially well off and willing to give free advice on finance. The people who are not financially secure will get the chance to learn how to pay bills without worry. The people volunteering financial advice in exchange will receive receipts from the people they helped so they can deduct this from their taxes. I think also that financially well-off folks would enjoy being able to teach others...." (Participant \#23, female, 38 years old)

From Fig. 3, we observe that markets focused on volunteer work where even more popular for both workers $(15 \%)$

and requesters $(23 \%)$ than crowd markets with a minimum wage set by workers. 
Figure 4. Overview of how workers and requesters configured the reputation feature in their crowd markets.

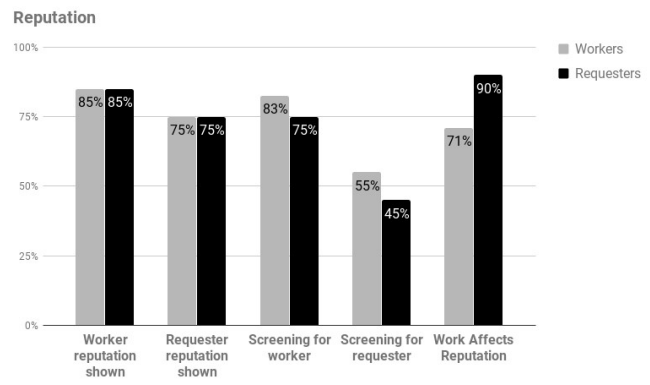

Reputation. From Table 2 and Fig. 4 we note that in general, workers $(82 \%)$ and requesters $(75 \%)$ wanted to screen workers (i.e., they planned to do background checks to investigate their workers' past reputation). Workers and requesters differed slightly (only by $5 \%$ ) on whether requesters should be screened. In general, over $40 \%$ of our participants planned to check anyone participating in their marketplace.

From Table 2, we also see that over $70 \%$ of workers and requesters envisioned markets where everyone's reputation was displayed. This is surprising considering that Amazon Mechanical Turk only showcases workers' reputation [45]. We also note that most workers and requesters wanted reputation to be affected by the work or interactions within the crowd market.

Figure 5. Overview of how workers and requesters configured the Work Schedule feature in their crowd markets.

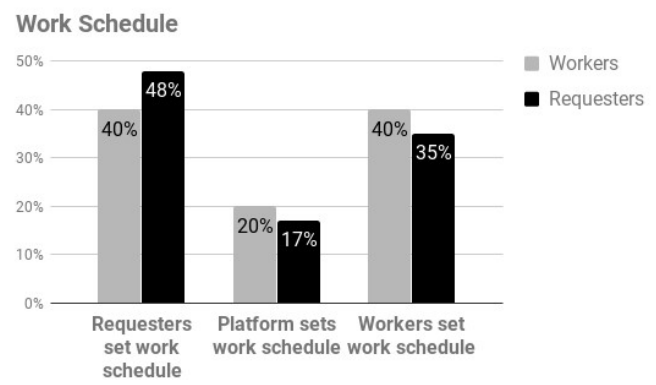

Work Schedule. From Table 2 and Fig. 5 we observe that workers $(40 \%)$ and requesters $(48 \%)$ pushed for crowd markets where requesters set the work schedule. However, an equal number of workers (40\%) also envisioned crowd markets where workers themselves controlled the work schedule. In these cases, their crowd markets focused more on providing services that could revolve around workers' time flexibility.

"... The workers are skilled tradesmen working in their spare time ..." (Participant \#10, male, 57 years old)

Very few workers and requesters opted for crowd markets where the platform determined the work schedule. In the few cases where they did, both workers and requesters tended to propose crowd markets that delivered real-time services that focused on requesters' needs.

"...My crowd market would provide real-time emergency psychological care for people who are depressed and suicidal. The platform in real time would connect depressed individuals with nurses and psychologists who would help diagnose and treat them instantly to avoid tragic ends ..." (Participant \#16, male, 24 years old)

\section{Discussion}

We built META-GIG as a design probe to indirectly question workers and requesters about what they currently lack in crowd markets. In this section, we will discuss some of the needs we identified through our study. We also make an effort to highlight the patterns we observed from the interactions of workers and requesters with META-GIG. We aim to provide relevant insights for designing future crowd markets, as well as tools that enable anyone to create their own crowd marketplace.

Hireability Needs. Most workers and requesters in our study envisioned hiring specialized workers. But, from where would these specialized workers come from?

Experts, in general, are rare [4]. While online work is on the rise [25], most experts are still not on crowd markets [9]. There is, therefore, opportunity in enabling marketplaces that facilitate expert participation [46]. Previous work had showcased that experts were more likely to complete crowd work if presented as micro-tasks. Future work might, therefore, look to develop more mechanisms [49][11] that break down specialized tasks into microwork where experts could complete as a side job. This might facilitate the insertion of more specialists into crowd markets, especially as experts would not need to leave their traditional jobs to participate.

We believe there is also opportunity in designing skill ladders on crowd markets through which any worker could one day become a specialist and hence also start to address the current lack of experts. While previous work [7][19], has started to study skill development within crowd markets, most approaches have relied on experts to educate novice crowd workers. There are opportunities in creating trainings through which workers can develop themselves without specialists [19][12]. This might also facilitate the long-term sustainability of crowd markets (as having to constantly recruit external experts would no longer be needed, and a larger number of workers might be able to access the training).

Future work might also look at enabling skill development while on the job to allow crowd workers to continue making money while training and developing themselves. This can be especially important considering that a great number of crowd workers make below minimum wage [28].

The least common crowd market where workers and requesters envisioned were markets with low-skilled remote labor, which is similar to what AMT currently offers. This is an interesting finding as it might suggest that in a near future not specialized individuals might have difficulties finding online work (as people might be more interested in pushing for specialized crowd labor). This further highlights the importance of enabling mechanisms through which workers can develop themselves and become specialists.

Our study also highlighted that both requesters and workers pushed for crowd markets that operated with locals. We believe there is opportunity in crowd market creation tools that can guide the creators of a market on the geographical locations where they might find the local workers they need. There might also be advantages for tools that can inform workers of the geographical locations where they are most likely to find their desired crowd work opportunities.

Wage Needs. Previous work has identified that crowd markets tend to operate with unfair wages [22], sometimes even with salaries that are far below minimum wage [28]. Our study revealed some interesting findings related to this point. Despite the prevalent low salaries in crowd markets, most workers (55\%) did not push to have a minimum wage on their marketplaces but instead pushed to 
have more agency over their own salary. Requesters similarly also tended to avoid crowd markets with a minimum wage $(73 \%$ envisioned alternative options). This result might suggest that future marketplaces seeking to impose a minimum wage might have some resistance from stakeholders.

We believe there are opportunities in crowd market creation tools that can create awareness among users about the decisions they are making for their markets. For instance, while some might believe that giving workers agency over their own salary can lead to better wages, research [50] has shown that individuals usually cannot ensure fair wages. Similarly, keeping low salaries can lead to having fewer individuals (especially qualified ones) willing to work on a platform [47]. For people pushing a minimum wage, it might similarly help to inform them that they will need to clearly define the conditions and the price models of their markets to make them viable [37]; especially as extra tariffs would need to be imposed to ensure that everyone receives a fair salary [1]. Here it might also help to communicate that ensuring a minimum wage can be difficult when the salary is based on supply and demand [6], as occurs in most crowd markets [29]; and having a minimum wage can result in overpriced services [23].

Almost $25 \%$ of the crowd markets that requesters proposed involved volunteer work (for workers this was $15 \%$, being the $3 \mathrm{rd}$ most common type of market that workers proposed). This result is surprising considering that the most well known crowd markets are usually commercial ones where workers receive a salary [40]. Volunteer-based crowd markets are more rare [18]. We believe there is value in further understanding the dynamics behind these volunteer-based crowd markets that people want to create. For what type of work do people want volunteer based crowd markets? How are people planning to motivate the long-term participation of volunteers on their platforms? We believe there is value in integrating prior social computing research [36] on motivating volunteers in online communities to now guide new crowd market creators on how to ensure their sustainability.

Reputation Needs. Our study revealed that the majority of workers and requesters sought to screen anyone they let on their platform as well as display their reputation on the site. We believe this result speaks about the need for trust that is currently lacking in crowd markets [35]. Previous research has highlighted how requesters do not trust workers to complete their tasks well; and workers do not trust requesters to pay them fairly [26, 27]. Our results are interesting because they hint that workers and requesters not only do not trust the other party, they also do not trust others like them and hence opt to screen everyone and display everyone's reputation. Similar to the minimum wage discussion, we believe there is value in tools that can inform market creators about the possible consequences and impact that screening and displaying everyone's reputation can have on their crowd markets, especially in terms of how it might facilitate or hinder diversity inclusion, platform sustainability and personal development of participants.

Future work might explore a more efficient way to score workers and requesters. As mentioned before, crowd markets' users are looking to share their background in order to build a more trustworthy community. If the reputation score systems are improved, we might stop needing this user screening in a long term in order to trust workers and requesters. One possible solution is to develop an algorithm that give preference connecting workers and requesters that have highly scored the other. On the other hand, if a requester poorly score the work of a worker, the algorithm will try to avoid as much as possible future interaction between them. This way, users will be motivated to properly score others based on future work exchanges. However, not every crowd market is suited for this user score system, therefore this will be a interesting work to do in the future.

Work Schedule Needs. In our study, both workers and requesters appeared more flexible to the work schedules defined by humans than of algorithms (i.e., platforms). Workers proposed an equal percentage of crowd markets ( $40 \%)$ that adapted to either the schedule of workers' or requesters'. While most requesters $(48 \%)$ did proposed crowd markets that revolved around their own schedule; an almost equal number (40\%) also pushed for markets that functioned around workers' schedule. Schedules focused on platform needs were rarer (only around $20 \%$ ). This is important to consider when we design future crowd markets. Current marketplaces mainly focus on providing immediate services whose timing is defined by a platform [16]. However, this might not be the most important priority for stakeholders.

We believe it is important to invest in the development of technologies that can conciliate "work completion times" either by the schedules of workers or of requesters given that complex scenarios can emerge depending on the chosen settings. For instance, for a task that a requester scheduled to be finished at midnight, who are the workers that should be invited to complete the work? Should it just follow a first come-first serve dynamic? Should the platform favor workers that are known to make those midnight deadlines? When should the requester be informed that the work is finished? (at the deadline he set, or once the work is done?).

It can also be important to help users be aware of when it is viable to use certain scheduling settings. For instance, a crowd market with a limited number of workers will need first to depend on its workers' availability. But, once its worker base increments it might be able to provide immediate services defined by an algorithm.

Future work might look to develop systems that better guide users to identify and recommend task scheduling mechanisms to optimize work schedules according to task duration, workers' availability, and requesters' urgency. This can also be important for helping workers and requesters to establish fair wages. It is also important for future work to consider enabling mechanisms to handle late work delivery, schedule disputes, and even mechanisms to prevent requesters in assigning unrealistic due dates in a crowd market [14].

The Future of Crowd Market Creation Tools. Through META-GIG, we are empowering less tech-savvy individuals to create the crowd markets they imagine. However, this can also lead to the implementation of design decisions that might not be the best and could bring inadequate labor conditions [39]. Such as creating screening processes that discriminate against minorities or force workers into low paying wages. As mentioned previously, we believe there is value in tools that can inform market creators of the impact their design decisions might have on workers and requesters based on the literature. It might also help to share best practices related to crowd market design.

Another of the main challenges that emerge with crowd market creation tools is ensuring that the markets that are created follow state or country-wise regulations associated with each niche of work [13]. These regulations might range from ensuring that certain salary conditions are met or that users' privacy is maintained (e.g., it might not be possible to share certain reputation information with third parties). Taxation is another risk that if handled improperly can result in legal problems for the crowd market. Businesses generally hire third-party companies to pay their taxes to ensure they follow all regulations across the different geographical locations where they operate [42]. Having third parties handle their 
taxes can be especially beneficial when working across regions where it can be difficult to understand all the policies that are in place. We believe there is value in tools that can inform new market creators about common practices to handle taxes and policy regulations across regions. Crowd-powered advice tools might be useful as there might be certain "tricks" that others have identified [8]. We also believe there is value in investigating tools that can inform users about the consequences of each of the settings they established in their crowd markets in regard to local regulations. In specific, we believe that tools that can inform users of how much effort is needed to scale their particular crowd markets to meet current regulations could be beneficial for end users.

Tools like META-GIG might help people to set up their own platforms, guiding users though the configuration process giving in-place advice over each feature, and make them aware of the impact of each decision over each stakeholder.

Future work can also explore how groups of workers and requesters (e.g., in unions) utilize tools such as Meta-GIG to collectively define the rules of their desired marketplace. Here we believe there is value in studying interfaces that can collectively help stakeholders decide how they want to configure their market: what exactly is each party willing to compromise? What does each party get to decide? Future work can also study their long-term sustainability.

\subsection{Limitations}

The insights from this work are limited by the methodology and population we studied. While our deployment allowed us to start understanding how workers and requesters interacted with systems like META-GIG, we cannot extrapolate to people unfamiliar with crowd markets when this approach gains popularity and is widely used. In such case, it might be relevant for future related systems to use our findings as a starting point for their explorations. Additionally, while we recruited real world workers and requesters, and all provided real-world project ideas, our results might not yet generalize to populations at large. Further analysis is also needed to understand how crowd market creation tools that leverage real workers could help to improve current working conditions. Experiments that compare the type of crowd markets that people generate when exposed to certain interfaces would help quantify more broadly the effect of including certain features and parameters in the crowd market ideas that people define. Future experiments that control local or remote based initiatives could be conducted to further understand what type of platform and parameters might facilitate adoption and promotes an improvement of actual models.

The goal of this paper was to shed light on what challenges and opportunities this type of platforms will face when people have governance of crowd markets. Future work could conduct longitudinal studies and engage in in-depth interviews with the different stakeholders to understand their motivations and perspectives of these type of systems and approaches. Future work could also explore how stakeholders react and benefit from the interaction of deployed crowd markets implemented after using META-GIG. As well as their overall impressions of such technology. Some interesting questions for future work to explore with the different stakeholders are: what are their main concerns when they start operating their crowd markets? What kind of guidance can help stakeholders to be more confident of what they are building? Do working conditions improve in some measurable way?

\section{Conclusions}

In this paper, we introduce META-GIG, a tool that enables crowd market stakeholders to define their own crowd market ideas. We described our approach in designing META-GIG and shared the lessons that we learned from deploying it with 40 crowd workers and 40 requesters. We focused on identifying design considerations for other crowd market designers building general-purpose platforms. As for META-GIG, future work will focus on the following features: exploring the implementation of the discovered features (e.g. payment, reputation, etc.), better handling of different types of ideas, and further focused on the stakeholders interests.

\section{References}

[1] G. A. Akerlof and J. L. Yellen, "The fair wage-effort hypothesis and unemployment," The Quarterly Journal of Economics, vol. 105, no. 2, pp. 255-283, 1990.

[2] M. Allahbakhsh, B. Benatallah, A. Ignjatovic, H. R. MotahariNezhad, E. Bertino, and S. Dustdar, "Quality control in crowdsourcing systems: Issues and directions," IEEE Internet Computing, vol. 17, no. 2, pp. 76-81, 2013.

[3] "Amazon Mechanical Turk" [Online]. Available: https://www.mturk.com/

[4] K. Balog and M. de Rijke, "Finding similar experts," in Proceedings of the 30th Annual International ACM SIGIR Conference on Research and Development in Information Retrieval, ser. SIGIR '07. New York, NY, USA: ACM, 2007, pp. 821-822. http://doi.acm.org/10.1145/1277741.1277926

[5] G. BÂRSAN, R. Oancea et al., "Considerations on ecommerce platforms," Alma Mater University journal, vol. 7, no. 1, pp. 16-20, 2014.

[6] J. Berg, "Income security in the on-demand economy: Findings and policy lessons from a survey of crowdworkers," Comp. Lab. L. \& Pol'y J., vol. 37, p. 543, 2015.

[7] J. P. Bigham, K. Williams, N. Banerjee, and J. Zimmerman, "Scopist: Building a skill ladder into crowd transcription," in Proceedings of the 14th Web for All Conference on The Future of Accessible Work, ser. W4A '17. New York, NY, USA: ACM, 2017, pp. 2:1-2:10. [Online]. Available: http://doi.acm.org/10.1145/3058555.3058562

[8] D. C. Brabham, Crowdsourcing as a model for problem solving: leveraging the collective intelligence of online communities for public good. The University of Utah, 2010.

[9] R. Brewer, M. R. Morris, and A. M. Piper, ""why would anybody do this?": Understanding older adults' motivations and challenges in crowd work," in Proceedings of the 2016 CHI Conference on Human Factors in Computing Systems, ser. CHI '16. New York, NY, USA: ACM, 2016, pp. 22462257. [Online]. http://doi.acm.org/10.1145/2858036.2858198

[10] M. Buhrmester, T. Kwang, and S. D. Gosling, “Amazon's mechanical turk: A new source of inexpensive, yet highquality, data?" Perspectives on psychological science, vol. 6, no. 1, pp. 3-5, 2011.

[11] J. Cheng, J. Teevan, S. T. Iqbal, and M. S. Bernstein, "Break it down: A comparison of macro-and microtasks," in Proceedings of the 33rd Annual ACM Conference on Human Factors in Computing Systems. ACM, 2015, pp. 4061-4064. 
[12] C.-W. Chiang, A. Kasunic, and S. Savage, "Crowd coach: Peer coaching for crowd workers' skill growth," in CSCW: ACM Conference on ComputerSupported Cooperative Work 2018., 2018.

[13] C. Codagnone and B. Martens, "Scoping the sharing economy: Origins, definitions, impact and regulatory issues," 2016.

[14] L. Dablanc, E. Morganti, N. Arvidsson, J. Woxenius, M. Browne, and N. Saidi, "The rise of on-demand "instant deliveries' in european cities," in Supply Chain Forum: An International Journal, vol. 18, no. 4. Taylor \& Francis, 2017, pp. 203-217.

[15] J. Davis, "Drive at your own risk: Uber violates unfair competition laws by misleading uberx drivers about their insurance covergae," BCL Rev., vol. 56, p. 1097, 2015.

[16] V. De Stefano, "The rise of the just-in-time workforce: Ondemand work, crowdwork, and labor protection in the gigeconomy," Comp. Lab. L. \& Pol'y J., vol. 37, p. 471, 2015.

[17] C. Dellarocas, "Analyzing the economic efficiency of ebaylike online reputation reporting mechanisms," in Proceedings of the 3rd ACM Conference on Electronic Commerce. ACM, 2001, pp. 171-179.

[18] A. Doan, R. Ramakrishnan, and A. Y. Halevy, "Crowdsourcing systems on the world-wide web," Communications of the ACM, vol. 54, no. 4, pp. 86-96, 2011.

[19] M. Dontcheva, R. R. Morris, J. R. Brandt, and E. M. Gerber, "Combining crowdsourcing and learning to improve engagement and performance," in Proceedings of the SIGCHI Conference on Human Factors in Computing Systems, ser. CHI '14. New York, NY, USA: ACM, 2014, pp. 3379-3388. [Online]. http://doi.acm.org/10.1145/2556288.2557217

[20] S. Dow, A. Kulkarni, S. Klemmer, and B. Hartmann, "Shepherding the crowd yields better work," in Proceedings of the ACM 2012 conference on Computer Supported Cooperative Work. ACM, 2012, pp. 1013-1022.

[21] E. Estellés-Arolas and F. González-Ladrón-De-Guevara, "Towards an integrated crowdsourcing definition," Journal of Information science, vol. 38, no. 2, pp. 189-200, 2012.

[22] N. Ettlinger, "Paradoxes, problems and potentialities of online work platforms," Work Organisation Labour \& Globalisation, vol. 11, no. 2, pp. 21-38, 2017.

[23] S. Faradani, B. Hartmann, and P. G. Ipeirotis, "What's the right price? pricing tasks for finishing on time." Human computation, vol. 11, p. 11, 2011.

[24] M. Feldman and A. Bernstein, "Cognition-based task routing: Towards highly-effective task-assignments in crowdsourcing settings," 2014.

[25] T. Ferro, K. Derthick, J. T. Morgan, E. Searle, and M. Zachry, "Understanding how people use publicly available online services for work," in Proceedings of the 27th ACM International Conference on Design of Communication, ser. SIGDOC '09. New York, NY, USA: ACM, 2009, pp. $311-$ 312. [Online]. http://doi.acm.org/10.1145/1621995.1622061

[26] S. N. S. Gaikwad, D. Morina, A. Ginzberg, C. Mullings, S. Goyal, D. Gamage, C. Diemert, M. Burton, S. Zhou, M. Whiting et al., "Boomerang: Rebounding the consequences of reputation feedback on crowdsourcing platforms," in
Proceedings of the 29th Annual Symposium on User Interface Software and Technology. ACM, 2016, pp. 625-637.

[27] S. N. Gaikwad, D. Morina, R. Nistala, M. Agarwal, A. Cossette, R. Bhanu, S. Savage, V. Narwal, K. Rajpal, J. Regino et al., "Daemo: A self-governed crowdsourcing marketplace," in Adjunct Proceedings of the 28th Annual ACM Symposium on User Interface Software \& Technology. ACM, 2015, pp. 101-102.

[28] K. Hara, A. Adams, K. Milland, S. Savage, C. Callison-Burch, and J. P. Bigham, "A data-driven analysis of workers" earnings on amazon mechanical turk," in Proceedings of the 2018 CHI Conference on Human Factors in Computing Systems. ACM, 2018, p. 449.

[29] M. Hu and Y. Zhou, "Price, wage and fixed commission in ondemand matching," 2017.

[30] P. G. Ipeirotis, "Analyzing the amazon mechanical turk marketplace," XRDS, vol. 17, no. 2, pp. 16-21, Dec. 2010. [Online]. http://doi.acm.org/10.1145/1869086.1869094

[31] P. G. Ipeirotis, F. Provost, and J. Wang, "Quality management on amazon mechanical turk," in Proceedings of the ACM SIGKDD workshop on human computation. ACM, 2010, pp. 64-67.

[32] L. Irani, "Difference and dependence among digital workers: The case of amazon mechanical turk," South Atlantic Quarterly, vol. 114, no. 1, pp. 225-234, 2015.

[33] A. Kittur, E. H. Chi, and B. Suh, "Crowdsourcing user studies with mechanical turk," in Proceedings of the SIGCHI conference on human factors in computing systems. ACM, 2008, pp. 453-456.

[34] A. Kittur, J. V. Nickerson, M. Bernstein, E. Gerber, A. Shaw, J. Zimmerman, M. Lease, and J. Horton, "The future of crowd work," in Proceedings of the 2013 conference on Computer supported cooperative work. ACM, 2013, pp. 1301-1318.

[35] M. Kokkodis, "Learning from positive and unlabeled amazon reviews: Towards identifying trustworthy reviewers," in Proceedings of the 21st International Conference on World Wide Web. ACM, 2012, pp. 545-546.

[36] R. E. Kraut, P. Resnick, S. Kiesler, M. Burke, Y. Chen, N. Kittur, J. Konstan, Y. Ren, and J. Riedl, Building successful online communities: Evidence-based social design. Mit Press, 2012.

[37] O. M. Levin-Waldman, The case of the minimum wage: Competing policy models. SUNY Press, 2001.

[38] J. Makkonen, C. Gracia, and V. Saarinen, The Lean Marketplace: A Practical Guide to Building a Successful Online Marketplace Business. Sharetribe, 2018.

[39] A. Malhotra and M. Van Alstyne, "The dark side of the sharing economy... and how to lighten it," Communications of the ACM, vol. 57, no. 11, pp. 24-27, 2014.

[40] A. Mao, E. Kamar, Y. Chen, E. Horvitz, M. E. Schwamb, C. J. Lintott, and A. M. Smith, "Volunteering versus work for pay: Incentives and tradeoffs in crowdsourcing," in First AAAI conference on human computation and crowdsourcing, 2013.

[41] D. Martin, B. V. Hanrahan, J. O'Neill, and N. Gupta, "Being a turker," in Proceedings of the 17th ACM conference on 
Computer supported cooperative work \& social computing. ACM, 2014, pp. 224-235.

[42] S.-Y. Oei and D. M. Ring, "Can sharing be taxed," Wash. UL Rev., vol. 93, p. 989, 2015.

[43] I. L. Office, International Standard Classification of Occupations 2008 (ISCO-08): Structure, group definitions and correspondence tables. International Labour Office, 2012.

[44] G. Paolacci, J. Chandler, and P. G. Ipeirotis, "Running experiments on amazon mechanical turk," 2010.

[45] E. Peer, J. Vosgerau, and A. Acquisti, "Reputation as a sufficient condition for data quality on amazon mechanical turk," Behavior research methods, vol. 46, no. 4, pp. 10231031, 2014.

[46] D. Retelny, S. Robaszkiewicz, A. To, W. S. Lasecki, J. Patel, N. Rahmati, T. Doshi, M. Valentine, and M. S. Bernstein, "Expert crowdsourcing with flash. teams," in Proceedings of the 27th Annual ACM Symposium on User Interface Software and Technology, ser. UIST '14. New York, NY, USA: ACM, 2014, pp. 75-85. [Online]. Available: http://doi.acm.org/10.1145/2642918.2647409
[47] J. Rogstadius, V. Kostakos, A. Kittur, B. Smus, J. Laredo, and M. Vukovic, "An assessment of intrinsic and extrinsic motivation on task performance in crowdsourcing markets." ICWSM, vol. 11, pp. 17-21, 2011.

[48] B. Satzger, H. Psaier, D. Schall, and S. Dustdar, "Stimulating skill evolution in market-based crowdsourcing," in International Conference on Business Process Management. Springer, 2011, pp. 66-82.

[49] J. Teevan, D. J. Liebling, and W. S. Lasecki, "Selfsourcing personal tasks," in CHI'14 Extended Abstracts on Human Factors in Computing Systems. ACM, 2014, pp. 2527-2532.

[50] Theintercept, "Trump administration fights effort to unionize uber drivers," Mar 2018. [Online]. Available: https://theintercept.com/2018/03/26/ uber-drivers-unionseattle/

M. E. Whiting, D. Gamage, S. S. Gaikwad, A. Gilbee, S. Goyal, A. Ballav, D. Majeti, N. Chhibber, A. Richmond-Fuller, F. Vargus et al., "Crowd guilds: Worker-led reputation and feedback on crowdsourcing platforms," arXiv preprint arXiv:1611.01572, 2016.

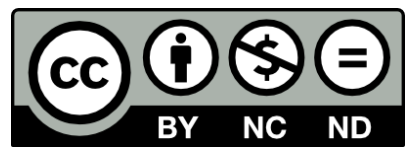

C 2020 by the authors. This work is licensed under the Creative Commons AttributionNonCommercial-NoDerivatives 4.0 International License. To view a copy of this license, visit http://creativecommons.org/licenses/by-nc-nd/4.0/ or send a letter to Creative Commons, PO Box 1866, Mountain View, CA 94042, USA. 